\title{
The Effect of Speed Reading on Students' Reading Comprehension
}

\section{(An Experimental Study in the Eleventh Grade of MAN Cibatu)}

\author{
Dadan Hidayat ${ }^{1}$
}

${ }^{1}$ English Faculty, Universitas Bina Sarana Informatika

\section{ARTICLE INFO}

Keywords:

Speed Reading

Reading Comprehension

\begin{abstract}
This research investigated the effect of speed reading on students' reading comprehension. The writer used quantitative as the research method and used the quasi experiment as a research design. The writer used experimental class to imply the speed reading method and control group for the other technique in teaching reading. For collecting the data the writer gave the pre - test for experimental and control group, then administrated the treatment for experiment class, finally the researcher administrated the post - test to find out the improvement of speed reading method for the student. Based on the writer interpretation it is concluded that hypothesis is accepted.it is suggested that the teacher should imply the speed reading method in teaching reading because research finding proved that speed reading gave more improvement in reading comprehension that the other technique in teaching reading and the speed reading method was more interesting than conventional method.
\end{abstract}

This is an open access article distributed under the terms of the Creative Commons Attribution 4.0 International License, which permits unrestricted use, distribution, and reproduction in any medium, provided the original work is properly cited. @ 2019 Dadan Hidayat.

\section{INTRODUCTION}

Reading is very useful to all people because they will get the information from their reading. But sometime the learners fell bored or stop to read if they find new vocabulary or difficult words from the book. The learners feel it because they don't know the technique of reading. The writer offers the solution to overcome the problem.

"Speed reading is not just about reading words faster than you did before. It is about being able to read at speed appropriate for the material you are reading. If you read to slowly your mind will wander, you may become bored and you won't remember anything. If you read to fast you will reduce the chances of remembering what you want to remember you will become frustrated and stressed and thus even less likely to remember ( konstant, 2003:25)."

\footnotetext{
${ }^{1}$ Corresponding author's address: English Faculty, Universitas Bina Sarana Informatika, Jakarta, Indonesia e-mail: Dadan.dhq@bsi.ac.id
} 
It proves that speed reading will benefit for the learner because they read the fast than slow because if they read slowly they will become bored. After that speed reading has the aims such as read faster, and maintains or increase comprehension (Bremer, 2011:131).

Speed reading gives benefit for the reader because the reader can read the fast and can comprehend the content on the book. According to (Wainwright, 2007:34) stat that:

"It is important to remember that reading speed and comprehension are not two separate elements in the reading process, but two parts of the same thing. Reading speed clearly refers to the speed of reading comprehension. Comprehension rather confusingly refers not only to the whole process of reading but also more specifically to the quality of reading comprehension."

The importance of speed reading has gained many attentions from some researcher. One of them they are; Takahiko (2012) the author analyses about effect of speed reading on English comprehension and vocabulary development. For his research paper reading comprehension were correlated with high speed reading. The other researcher is Margherita (2012) the researcher wants to discover reading accuracy through speed reading as a predictor of later literacy and the comprehension. The next author is Jennifer (2012) the author investigated Maze and reading comprehension rate measures are calculated by using measures of reading speed and measures of accuracy. And then Rachel (2012) the author explored about the speed accuracy, and reading comprehension and the author analyses about the effect for children mastery of vowelized reading speed and accuracy on their mastery of vowelized reading speed.

However, the researcher reported in the previous paragraph was only conducted about the speed reading as a predictor, speed reading as an accuracy to comprehend the content and then the speed reading as method in comprehension. These studies have only dealt with the situation in speed reading as a predictor in reading comprehension, whereas the writer focuses on student reading comprehension through speed reading. Because the writer wants to know what student gets after the student use speed reading method.

Using speed reading on student reading comprehension is investigated in this research, and then the research question for this study are;

1. Does speed reading improve students reading comprehension?

2. How does speed reading give affect for student reading comprehension?

\section{Definition of Reading}

"Reading is about understanding written texts. It is a complex activity that involves both perception and thought. Reading consists of two related processes: word recognition and comprehension. Word recognition refers to the process of perceiving how written symbols correspond to one's spoken language. Comprehension is the process of making sense of words, sentences and connected text (Bernbardt 2003:6):

\section{How to Teach Reading}

Johnson (2005:11-13), stated that tips to keep in mind as we create good reading conditions. And here are the tips to create a good condition in teaching reading.

1. The first the teacher must be able to make children fall in love with books.

2. The second create a space every day for sustained silent reading.

3. The third allow children to make choices about their reading material.

4. The fourth connect reading pleasure to reading practice.

5. The fifth keep your reading program simple.

6. The six keep instruction simple.

The last for tips in teaching reading, the teacher have to make reading like real life

\section{Six parts of Effective Reading}

According to Whitely (2004: 10) stated that parts of effective reading are: alphabetic, vocabulary, fluency, skimming, and speed control. The following explanation will discuss each stage in detail. 
1. Alphabetic: for this section the reader will recognize letters and words accurately.

2. Vocabulary: in this section the reader tries to understand the meaning of words in context.

3. Fluency: for the third of part effective reading is fluency and the reader has to read word and sentence fluency.

4. Skimming: select what to read while reading.

5. Speed control: for this part the reader try to read vary speed content and purpose.

\section{Speed Reading}

Many authors have been giving kind definition of speed reading. One of them is given by Konstan (2003:25) which stated that Speed reading is not just about reading words faster than you did before. It's about being able to read at speed appropriate for the material you are reading."

After the reader uses the speed reading method to comprehend the content on the book. They will get the advantages such as: they will read the fast than slowly because the speed reading has the aim. They are; Read faster and maintain or increase comprehension (Bremer, 2011: 131).

\section{Types of Speed Reading}

Bremer (2011:132) stated that the speed reading can be divided in two types, they are;

1. Traditional speed reading.

2. Subconscious Photographic-type reading.

These stages focus on types of speed reading. The following explanation will discuss each stage in detail,

1. Traditional speed reading.

This types of speed reading focuses on improving the mechanics of reading to minimizing regression during reading, usually through the use of guide, this types focus of reducing sub vocalization and capturing more words with each glance. The approach involves performing drills daily in order to maintain the skill.

\section{Subconscious Photographic-type reading}

The second types of subconscious photographic- types involves using the subconscious mind in order to capture the information, is a more recent development (though some courses date back to the 1970s) and it offers a very different approach to reading when compared to the traditional speed reading courses.

\section{Technique of Speed Reading}

This section discusses the technique of speed reading. The technique of speed reading based on Bremer (2011:135- 143) stated that the reader is advised not to try and extract hidden ideas or deeper meaning (since there are none) but to just follow the procedure as instructed, focusing mainly on the reading. The key ingredients to the system are as follows:

1. Concentration on the reading and blocking out distractions.

2. Avoiding regressions.

3. Reducing sub-vocalization.

4. Capturing more words with each fixation.

5. Using layered reading.

6. Using subconscious reading for increased familiarity with a topic.

\section{Using pacer in speed reading}

In speed reading process there is a tool to make the reader more focus in reading process. Then the simple tool is the pacer. According to Konstant (2003: 38-39) ) the pacer is the simple tool that will help you to eliminate of your speed reading problem. A pacer can be your finger, a chopstick, a pencil or pen- anything you can use to help you focus your attention in reading process. Pacer helps your reading in several ways: a pacer encourage your eyes to focus on more than one word at a time. After that a pacer make you focus on what you are reading instead of allowing your eyes to jump around the page at anything that attracts your attention. 
After that the pacer can help the reader like that: Move to new lines smoothly and easily, Prevent you losing your place, Prevent sub - vocalization. Then the pacer as a simple tool in speed reading process. The reader can use the pacer like the step below:

1. Place your pacer on the first word on the line and move it smoothly across the page to the end of the line, then return in to the next line.

2. Use pacer to read the boxed paragraph. Take a pacer a place this pacer on dotted line and move it smoothly along the line across the page. After that re -Ed this paragraph several times until you feel that you have the rhythm smooth and fast - also, move this pacer just a title bit quicker than you think you can read.

\section{Reading Comprehension}

For this section the writer discuss about reading comprehension and the writer want to know what the reader get after they use speed reading on student comprehension. Reading consists of two related processes. Word recognition and comprehension. The writer focuses to discuss about reading comprehension. Based on Bernbardt (2003: 6) which stated that Comprehension is the process of making sense of words, sentences and connected text.

After that reading comprehension is usually the ultimate goal of reading. You want to understand and learn what the author is communicating. Then there are many factors to comprehend the content on the book. Based on Whitely (2004: 65) which stated that there are many factors to comprehend the content from this book. Bellows are factor in reading comprehension:

1. The first factor in reading comprehension you're reading level and vocabulary.

2. The second your previous understanding of the topic.

3. The third factor is how long it takes you to read the material.

4. The fourth your concentration levels.

5. The fifth your "world knowledge."

6. The six factor of reading comprehension you're learning and memory skills.

7. And for the last factor of reading comprehension is your motivation.

\section{Improving Comprehension}

Some expert gives the solution to improve the reading comprehension. One of them is the Wainwright; (2007: 46) stated that you can improve the quantity and quality of your comprehension in three main ways:

1. Firstly, you can improve it by wide varied reading, where variety is more important than volume.

2. Secondly, you can improve it by discussion.

3. Thirdly, you can improve it by testing.

The following explanation will discuss each stage in detail about the three main ways in comprehension:

1. Improve it by wide varied reading, where variety is more important than volume.

2. improve comprehension by discussion:

In discussion, your comprehension is immediately either reinforced or rejected. If others agree with you and you have clearly understood what you were reading, this reinforces the impression the material makes and assists later recall. If others disagree with you and you have clearly misunderstood what you were reading, this is in a sense even better. You can add their understanding to replace and argument your own so that you emerge from the discussion with more than you went in with.

3. You can improve it by testing:

You might not notice improvement in the course of working through the exercises in this book because they are graded to offer a gently rising level of difficulty in an attempt to counter the effects of improving simply through practice.Base on the explanation above the writer conclude 
that this step is good to try by the reader to improve their reading comprehension and increase their skill in reading.

\section{Reading for Comprehension and Speed}

For this section the writer discusses about the correlation between the reading for comprehension and speed because Reading comprehension is two part element in reading process and then based on Whitely (2004: 9) to comprehend what you read, you need to read the words. Skim reading, or skipping some words, does help with the learning process, and helps locate important information quickly. However, your comprehension suffers.

Based on the explanation above the writer conclude that the reader can read fast in simple technique, without need the software, machine, hypnotherapy and the other to keeping up their reading comprehension. Therefore to get the information from their reading they have to learn the reading process because in reading comprehension the reader is not enough to read. Then they have to remember what you read and learn what you read to get knowledge from their reading.

\section{RESEARCH METHODOLOGY}

For research method the writer used the quantitative method, because the writer need the data' to be analyzed using mathematically based method in particular statistic' (Muijs, 2004:1).Then in quantitative research method the writer gave the test for this research and the data was analyzed' by examining the relationship among variable. These variables, in turn, can be measured, typically on instruments, so that numbered data can be analyzed using statistical procedures (Creswell 2009: 4). It's clear that quantitative method suitable to use for this research.

For research design the writer used the quasi - experiment for experimental research because quasi suited to look at the effect of an educational intervention, such as a school improvement programmed, a project to improve a specific element (such as an anti- bullying programmed) or a professional development programed (Muijs, 2004:27). The writer used two classes for experimental research. One group is experimental groups (EG) which gave the treatment with speed reading in learning process. And another is control group (CG) which gave the treatment which another reading technique. Based on explanation above the writer used the quasi experiment for experimental research because the writer tried to find out the effect of an educational intervention, such as a school improvement programmed, a project to improve a specific element. For this section the writer want to know the effect of speed reading method on student reading comprehension. The independent variable for this research is the effect of speed reading, and the dependent variable for this research is students reading comprehension.

For this research the writer need the population and sample because the population for a study is that group (usually of people) about whom we want to draw conclusions. (Babbie, 2010:116). The population for this research is the students in a state senior high school. The writer took the sample from two classes. Then for the sample technique the writer used a cluster sampling technique because the writer used this sample based on the cluster. Then for sample the writer used the cluster from second grade as the samples. And the sample took from eleven classes.

For this research, the writer has the following procedures to get data. There were several steps which implemented on identifying students' comprehension before and after giving speed reading in teaching reading. The research procedures are:

1. Administering pre-test

2. Conducting the SPEED READING treatment to the experimental group.

3. Conducting the extensive reading treatment to the control group.

4. Administering post-test to both of the group.

For the Data AnalysisThe data collected by means of the test instruments, were analyzed differently according to specific purposes. In this case, two kinds of analyses were carried out: (1) 
test instrument analysis, (2) pre-test post-test data analysis. The description of data analyses procedures.

A good instrument is very useful in research. The analyses of the test instruments are:

Validity, reliability, difficulty and discrimination index.

\section{Validity}

The validity is the extent to which the data accurately measures what they were intended to measure. Then for the formula as follows:

$r_{X Y}=\frac{n\left(\sum X Y\right)-\left(\sum X\right) \cdot\left(\sum Y\right)}{\sqrt{\left\{n \cdot \sum X^{2}-\left(\sum X\right)^{2}\right\} \cdot\left\{n \cdot \sum Y^{2}-\left(\sum Y\right)^{2}\right\}}}$

Note:

$\mathrm{r}_{\mathrm{xy}}=$ coefficient correlation between variable $\mathrm{X}$ and $\mathrm{Y}$

$\mathrm{X}=$ item which its validity is assessed

$\mathrm{Y}=$ total score gained by the sample

(Sundayana : 2000).

Even though, in this study SPSS 16 was applied to measure

\section{Difficulty, Reliability, Discrimination index.}

The next analyses of the test instruments are difficulty, reliability, and discrimination index. To analyses these instruments the writer used the Ana test program. The Ana test program is the software from the computer. The aim for antes program is to analyses the test instrument such as the reliability, difficulty and discrimination index. This program is simple to use. Then for the analyses of test instrument the writer used this program.

\section{Data Analysis Pre - test and Post - test}

Before analyses the data pre -test and the post -test or performing the independent t-test, the output data of the pre-test should fulfill the criteria underlying t-test:

1. The data should have a normal distribution

2. The variance of the two groups must be homogenous

3. Testing hypothesis about the difference between two dependent means

For that reason, normal distribution test, homogeneity of variances test, and independent $t$-test were performed before calculating the data using t-test formula

\section{Normality of Distribution Test}

To analyze the distribution of the score, the writer use the excel program on the computer to analyses the distribution score. If the Lmaks < Ltable so this data is normal.

\section{Homogeneity test}

After the analyses of the normality of distribution test. The writer did the homogeneity of variance test. In an experimental research, one of requirements that should be fulfilled is experimental group and control group must be homogenous or having same characteristic. The formula is as follows:

$$
F_{\text {value }}=\frac{\text { highest variance }}{\text { lowest variance }}
$$

Variance is the square of standard deviation, so the result of the equation is the $F_{\text {value. This }} F_{\text {value }}$ then to be compared to $F_{\text {crit, }}$ the hypothesis are:

$\mathrm{H}_{0}$ : There is no significant effect of speed reading on students reading achievement.

$\mathrm{H}_{\mathrm{a}}$ : There is significant effect of speed reading on students reading achievement. 
The decision of variance homogeneity is as $\mathrm{F}_{\text {value }}<\mathrm{F}_{\text {table, }} \mathrm{H}_{0}$ is accepted. On the contrary; as $\mathrm{F}_{\text {value }}<$ $\mathrm{F}_{\text {table, }} \mathrm{H}_{0}$ is rejected (Sundayana: 2012).

\section{Testing Hypothesis about the Difference Between two Dependent Means}

To count the testing a hypothesis about two dependent meant, the writer use the $t$ test: the process of computation is divided in two parts. first we find the basic quantities from which the rest of the calculation flow: $\sum x, \sum_{x} 2, \sum y, \sum_{y} 2$, and $\mathrm{n}$. Next, we calculate the mean in step(1), the estimated population standar daviation in step (2), and (3), the correlation coefficien instep (4), the estimated standard error of the means in step (5), the estimated standard error of the difference between the means in step (6), and finally $t$ in step (7).

The calculation:

$$
\begin{aligned}
& \text { (1). } \bar{x}=\frac{\sum x}{n} \\
& \text { (2). SSx }=\sum_{x} 2-\frac{\left(\sum x\right) 2}{n} \\
& \text { (3). } \mathrm{sx}=\frac{\sqrt{s s x}}{n-1} \\
& \text { (3a). SSy }=\sum_{y} 2-\frac{\left(\sum y\right) 2}{n} \\
& \text { (3b). Sy }=\frac{\sqrt{s s y}}{n-1} \\
& \text { (4a). } \sum(x-\bar{x})(y-\bar{y})=\sum x y-\frac{\left(\sum x\right)\left(\sum y\right)}{n} \\
& \text { (4b). } \mathrm{r}=\frac{\sum(x-\bar{x})(y-\bar{y})}{\sqrt{(s s x)(s s y)}} \\
& \text { (5a). } \mathrm{s} \bar{x}=\mathrm{sx} / \sqrt{n} \\
& \text { (5b). } \mathrm{s} \bar{y}=\mathrm{sy} / \sqrt{y} \\
& \text { (6). } \mathrm{s} \bar{x}-\bar{y}=\sqrt{S \frac{2}{x}+S \frac{2}{Y}-2 r s}-2 \mathrm{rs} \bar{x} \mathrm{~s} \bar{y} \\
& \text { (7). } \mathrm{t}=\frac{(\bar{x}-\bar{y})-(\mu x-\mu y) h y p}{s \bar{x}-\bar{y}}
\end{aligned}
$$

(Minium, 327:1970)

\section{FINDING AND DISCUSSION}

Table 1. The Interpretation of difficulty index from pre - test

\begin{tabular}{cc}
\hline The interpretation & Number of item \\
\hline Easy & 8 \\
\hline Medium & $1,2,3,4,5,6,7,9$ \\
\hline Difficult & 10
\end{tabular}

From the test, it was found that eight items were medium, one item was difficult and one item was easy.

Table 2. The interpretation of difficulty index from post - test

\begin{tabular}{cc}
\hline The interpretation & Number of item \\
\hline Medium & $1,2,3,4,5,6,7,8,9$ \\
\hline Difficult & 10 \\
\hline
\end{tabular}

Table 3. The interpretation of Discrepancy Level from pre - test

\begin{tabular}{cc}
\hline The interpretation & Number of item \\
\hline Best & 4,10 \\
\hline
\end{tabular}




\begin{tabular}{cc}
\hline Good & $1,2,3,5$ \\
\hline Moderate & $6,7,8,9$ \\
\hline
\end{tabular}

From the test it was found that two items were best. Four items were good and four items were moderate.

Table 4. The interpretation of Discrepancy Level from post - test

\begin{tabular}{cc}
\hline The interpretation & Number of item \\
\hline Best & 9 \\
\hline Good & $1,2,3,4,5,6,7,8$ \\
\hline Moderate & 10 \\
\hline
\end{tabular}

From the test it was found that one item was best. Eight items were good and one item was moderate.

\section{The Validity}

To analysis the validity of the instruments the writer used the program excels from the computer. The analysis of validity is important to researcher because the validity is a term describing a measure that accurately reflects the concept it is intended to measure (Babbie 2010: 153)

Table 5. The category of validity of pre - test

\begin{tabular}{cc}
\hline Category & Number of Item \\
\hline Significant & $1,2,3,4,5,6,7,10$ \\
\hline Not significant & 8,9 \\
\hline
\end{tabular}

From the table above it was obtained that eight items were significant and two items were not significant. The total items that were used in the instrument were eight numbers: 1, 2, 3, 4, 5, 6, 7 and 10. It was concluded that the writer used the number which significant, while the item which not significant were not used.

Table 6 . The category of validity of post- test.

\begin{tabular}{cc}
\hline Category & Number of Item \\
\hline Significant & $1,2,3,4,6,7,8,9$ \\
\hline Not significant & 5,10 \\
\hline
\end{tabular}

From the table above it was obtained that eight items were significant and two items were not significant. The total items that were used in the instrument were eight numbers: 1, 2, 3, 4, 6, 7, 8 and 9. It was concluded that the writer used the number which significant, while the item which not significant were not used.

\section{Reliability Test}

Reliability of pre - test.

The reliability of the instrument was analyzed by using the Anates V4 program. From the computation it was resulted 0.25 reliability test. It was concluded that the result from the reliability test was low reliable.

Reliability of post - test. 
The reliability of the instrument was analyzed by using the Anates V4 program. From the computation it was resulted 0.47 reliability test. It was concluded that the result from the reliability test was medium reliable.

Based on the computations above, the total item was used on instrument of pre - tests were eight numbers: 1, 2, 3, 4, 5, 6, 7 and 10 .Then the total item used on instrument of post - tests were eight numbers: $1,2,3,4,6,7,8$ and 9 .

Pre - test

The pre-test was conducted on 30 April 2013. It was administered to the experimental group and control group with 31 students each. The aim of pre-test was to measure students' on reading comprehension before giving the treatment. For the pre- test the writer gave the multiple choices for the student. The result score of experimental and control group on the pre -test can be seen in following table.

Table 7. The pre - test score of experimental and control group

\begin{tabular}{cccccc}
\hline Group & $\begin{array}{c}\text { Number of } \\
\text { respondent }\end{array}$ & Mean & $\begin{array}{c}\text { Max } \\
\text { score }\end{array}$ & $\begin{array}{c}\text { Min } \\
\text { score }\end{array}$ & $\begin{array}{c}\text { Standar } \\
\text { deviation }\end{array}$ \\
\hline $\begin{array}{c}\text { Experimental } \\
\text { group }\end{array}$ & 31 & 5.218 & 10 & 2.5 & 2.114 \\
\hline Control group & 31 & 5.403 & 10 & 2.5 & 2.268 \\
\hline
\end{tabular}

From the table above it was found that the mean score from control group $>$ from the experimental group. After that the writer wanted to know that the data were normally distributed or not normally distributed, so the writer continued to analysis this data with normally test.

Normality test

In this research the normality of pre -test reading comprehension was tasted by using liliefors with level significant $\alpha 0.05$ the result from normality of pre -test can be seen in following table.

Table 8 . The result of normality test of pre -test

\begin{tabular}{|c|c|c|c|}
\hline \multirow{2}{*}{ Pre- test } & \multicolumn{2}{|c|}{ Value $\mathrm{X} 2$} & \multirow[t]{2}{*}{ Criteria } \\
\hline & Lmax & Lcrit & \\
\hline Experimental & 0.143 & 0.161 & Normal \\
\hline Control & 0.158 & 0.161 & Normal \\
\hline
\end{tabular}

The criteria of normally distributed, if Lmax < Lcrit so the data could be said normally distributed. While if Lmax $>$ Lcrit the data were not normally distributed. From the table above the Lmax $<$ from Lcrit so it was concluded that the data were normally distributed. Because both data were normally distributed so the researcher continued to analysis this data with homogeneity test.

Homogeneity test

Table 9. Homogeneity test on pre - test

\begin{tabular}{cccc}
\hline Class & Variance & Fcount & Fcrit \\
\hline Experimental & 4.000 & 1.134 & 1.84 \\
\hline Control group & 3.527 & &
\end{tabular}

The criteria of homogeneity test if fcount $\leq$ fcrit so was homogent. Based on table above it was concluded that the data was homogent. After that the writer continued to analyze the data with testing a hypothesis about two dependent means.

\section{Testing a hypothesis about two dependent means}

Table 10. The result of testing a hypothesis about two dependent means

\begin{tabular}{cccc|}
\hline Pre - test & Mean & tvalue & tcrit \\
\hline
\end{tabular}




\begin{tabular}{cccc|}
\hline Experimental & 5.218 & 0.527 & 2.0423 \\
\hline Control group & 5.403 & & \\
\hline
\end{tabular}

From the table, it was found that tvalue was 0.527 which were more than $\alpha 0.05$ it means that Ho is accepted. So, it was concluded that there is no significant difference between experimental and control group before speed reading method was applied for the experimental and the other method of teaching reading for control group

\section{Post-test}

It was conducted on 15 May 2013 for experimental group and control group. The item in post-test consisted of multiple choices. For the post - test item was the same with the pre -test but the content was different from pre - test. Aim of post-test was to measure students' on reading comprehension after giving the treatment from each method in teaching reading. The result of mean score from experimental and control group on the pre -test can be seen in

Table 11. The post - test score of experimental and group.

\begin{tabular}{cccccc}
\hline Group & $\begin{array}{c}\text { Total of } \\
\text { respondent }\end{array}$ & Mean & $\begin{array}{c}\text { Max } \\
\text { score }\end{array}$ & $\begin{array}{c}\text { Min } \\
\text { score }\end{array}$ & Deviation \\
\hline $\begin{array}{c}\text { Experimental } \\
\text { group }\end{array}$ & 31 & 7.097 & 10 & 3.75 & 2000 \\
\hline Control group & 31 & 4.395 & 7.5 & 1.25 & 1.878 \\
\hline
\end{tabular}

\section{Normality test}

In this research the normality of post -test reading comprehension was tasted by using liliefors with level significant $\alpha 0.05$ the result from normality of post -test can be seen in following table.

Table 12. The result of normality test of post-test

\begin{tabular}{|c|c|c|c|}
\hline \multirow[t]{2}{*}{ Post - test } & \multicolumn{2}{|c|}{ Value X2 } & \multirow[t]{2}{*}{ Criteria } \\
\hline & Lmax & Lcrit & \\
\hline Experimental & 0.140 & 0.161 & Normal \\
\hline Control & 0.150 & 0.161 & Normal \\
\hline
\end{tabular}

The criteria of normally distributed, if Lmax < Lcrit so the data were normally distributed. While if Lmax > Lcrit the data were not normally distributed. From the table above the Lmax < from Lcrit so it was concluded that the data were normally distributed. Because both data were normally distributed so the researchers continued to analysis this data with homogeneity test

Homogeneity test

Table 13. Homogeneity test on post - test

\begin{tabular}{cccc}
\hline Class & Variance & Fcount & Fcrit \\
\cline { 1 - 2 } Experimental & 4.468 & \multirow{2}{*}{1.151} & 1.84 \\
\hline Control group & 5.143 & & \\
\hline
\end{tabular}

The criteria of homogeneity test if fcount $\leq$ fcrit so was homogent. Based on table above it was concluded that the data was homogent. After that the writer continued to analyze the data with testing a hypothesis about two dependent means

\section{Testing a hypothesis about two dependent means}

Table 14. The result of testing a hypothesis about two dependent means

\begin{tabular}{|c|c|c|c|}
\hline Pre - test & Mean & tvalue & tcrit \\
\hline Experimental & 7.097 & 7.005 & 2.0423 \\
\hline Control group & 4.395 & & \\
\hline
\end{tabular}


From the tables, it is found that tvalue was 7.005 which was more than $\alpha 0.05$ it means that Ho is rejected. So, it can be concluded that there is a significant difference between experimental and control group after speed reading method was applied for the experimental and the other method of teaching reading for control group.

To answer the research question for this paper are answered by using quantitative finding. Then question for this research are;

1. Does speed reading improve students reading comprehension?

2. How does speed reading give effect to student reading comprehension?

The quantitative finding answered this question. Based on the quantitative finding that speed reading method improves students reading comprehension. Then for the second answer it can looked from the quantitative finding that there is effect of speed reading method on student reading comprehension after speed was applied. It is proved by the student score from post -test. The score from the experimental $>$ control group score.

\section{CONCLUSION}

There are several points which can be drawn from the present study. First, speed reading method is effective in improving students' reading comprehension. It means that the formulation of hypothesis in Chapter 1 is accepted.

Speed reading more effective for improving student reading comprehension. It can be concluded that speed reading method can used by the teacher in teaching reading activity to improve their reading comprehension.

\section{BIBLIOGRAPHY}

Babbie. (2010). The Practice of Social Research. USA: Chapman University..

Creswell. (2009). Research Design. United Kingdom: sage.

jain, P. a. (2008). English Language Teaching. Sunrise Publisher.

Johnson. (2008). Teaching Reading and Writing. United Kingdom: Manufactured in the United States of America.

Konstan. (2009). teach yourself speed reading. UK: Hodder HIdeline.

Margherita. (2012). Speed Reading. Eric Journal.

Minium. (1993). Statistical Reasoning in psychology and Education.

Muijs. (2004). Doing Quantitative Research In Education. London: SAGE publication.

Sundayana. (2012). Komputasi dan Statistica. Garut: STKIP Garut Press.

Wainwright. (2007). how to read Faster And Recall More. United Kingdom.: How To Content,.

Whiteley. (2004). Effective Speed Reading Course. Advanogy.com. 